\title{
Medidas tributarias para afrontar el covid-19 en Colombia
}

\author{
Tax measures to tackle Covid-19 \\ in Colombia
}

\author{
Medidas fiscais para combater o \\ Covid-19 na Colômbia
}

Ana Cristina Triana SuÁrez

\footnotetext{
Magíster en Tributación Internacional, Comercio Exterior y Aduanas de la Universidad Externado de Colombia. Auditora de Fiscalización Tributaria, Cambiaria y Aduanera de la Dirección de Gestión de Fiscalización de la Dirección de Impuestos y Aduanas Nacionales (DIAN). Miembro Grupo de Investigación Conocimientos Tributarios Latam. acritisu06@hotmail.com / https://orcid.org/0000-0002-0599-3182

DoI: https://doi.org/10.18601/16926722.n18.04
} 


\title{
Resumen
}

El covid-19 poco a poco ha ido invadiendo todos los territorios y América Latina no es la excepción. Colombia estableció medidas de orden fiscal con el fin de facilitar, apalancar y aliviar en parte los efectos económicos generados por esta emergencia. Estos mandatos son el objetivo central de este escrito, en el cual se describen y se analiza su incidencia en el recaudo tributario y cumplimiento fiscal por parte de los administrados.

Palabras clave: covid-19; impuestos; tributo; pandemia; tax; Colombia.

\begin{abstract}
In 2020, the world is being hit by COVID-19, gradually invading all the territories, reaching the region of Latin America, which today registers 840,000 cases and positioned itself as a focus of the coronavirus pandemic, Colombia contributes 24,104 of these cases, this has led to taking different health measures that paralyzed the economy, within these provisions some of the tax order were adopted, in order to facilitate, leverage and alleviate in part the economic effects generated by this health emergency; these mandates are the central objective of this letter, which describes and analyses its impact on tax collection and tax compliance by the administered.
\end{abstract}

Key words: CoviD-19; taxes; exemption; exclusion; pandemic.

\section{Resumo}

Em 2020, o mundo está sendo atingido pelo CoviD-19, invadindo gradualmente todos os territórios, atingindo a região da América Latina, que hoje registra 840 mil casos e se posicionou como foco da pandemia coronavírus, a Colômbia contribui com 24.104 desses casos, o que levou a tomar diferentes medidas de saúde que paralisaram a economia , dentro dessas disposições, parte da ordem tributária foi adotada, a fim de facilitar, alavancar e aliviar, em parte, os efeitos econômicos gerados por essa emergência sanitária; esses mandatos são o objetivo central desta carta, que descreve e analisa seu impacto na arrecadação de impostos e na conformidade fiscal pelos administrados.

Palavras chave: CoviD-19; impostos; isenção; exclusão; pandemia. 


\section{Introducción}

El crecimiento acelerado y exponencial del covid-19 llevó a que se tomaran disposiciones para frenar su expansión en Colombia, con las cuales se paralizó la economía como consecuencia de la adopción de las medidas sanitarias de aislamiento obligatorio y cierre fronterizo.

Estas normas fueron adoptadas dentro del estado de excepción de emergencia económica, social y ecológica declarado mediante Decreto 417 del 17 de marzo de 2020 y Decreto 637 del 6 de mayo de 2020, y la Emergencia Sanitara pronunciada por medio de las Resolución 385 del 12 de marzo de 2020 del Ministerio de Salud, prorrogada según Resolución 844 del 26 de mayo de 2020, con vigencia hasta el 31 de agosto de 2020.

Dentro de estos mandatos se incorporan algunos propios del ámbito fiscal, con el fin de aliviar los efectos de la contingencia sanitaria. Con estas medidas adoptadas se busca facilitar el cumplimiento de las obligaciones tributarias y los procedimientos de la administración tributaria, proporcionar apalancamiento financiero para la liquidez y el alivio de caja para el aparato producto y los hogares colombianos.

Así las cosas, el presente escrito da cuenta de las medidas tomadas por el gobierno colombiano en el ámbito fiscal para mitigar los efectos de la pandemia.

\section{Medidas referentes a prescripciones y plazos}

\section{A. Modificación y ampliación de plazos para la presentación y el pago de las declaraciones tributarias}

Con los decretos 401 del 13 de marzo y 435 del 19 de marzo de 2020, se amplió el plazo para presentar la declaración del bimestre 2 y cuatrimestre 1 del impuesto sobre las ventas para las empresas y personas naturales que ejecuten las actividades de:

- Transporte aéreo nacional.

- Sector hotelero.

- Teatros.

- Espectáculos musicales en vivo.

- Otras actividades de espectáculos en vivo.

- Operación turística.

- Agencia de Viajes.

Igualmente, a través del Decreto 435 del 19 de marzo de 2020 se amplió el plazo para presentar la declaración del bimestre 2 del impuesto nacional al consumo para las empresas y personas naturales que ejecutan la actividad de expendio de comidas y bebidas en cafeterías, restaurantes y bares. 
Asimismo, los decretos 435 del 19 de marzo y 520 del 06 de abril de 2020 ampliaron el plazo para presentar la declaración y pagar las cuotas del impuesto de renta del año gravable 2019, así:

- Grandes contribuyentes, el pago de la segunda cuota desde el 21 de abril hasta el 05 de mayo y el pago de la tercera cuota y presentación de la declaración desde el 09 de junio hasta el 24 de junio.

- Personas jurídicas el pago de la primera cuota desde el 21 de abril hasta el 05 de mayo y el pago de la segunda cuota y presentación de la declaración desde el 01 de junio hasta el 01 de julio.

De igual forma, el Decreto 655 del 13 de mayo de 2020 adoptó un plazo especial para la presentación y el pago de la declaración de impuesto de renta del año gravable 2019 de las Mipymes clasificadas de acuerdo con el Decreto 1074 de 2015 (tabla 1).

Tabla 1. Clasificación Mipymes, Decreto 1074 de 2015

\begin{tabular}{|c|c|c|c|c|c|c|}
\hline $\begin{array}{l}\text { Clasificación } \\
\text { Mipymes } \\
\text { Tipo de } \\
\text { actividad }\end{array}$ & \multicolumn{2}{|c|}{ Manufactura } & \multicolumn{2}{|c|}{ Servicios } & \multicolumn{2}{|c|}{ Comerciales } \\
\hline Microempresa & Inferior & 23.563 UVT & Inferior & 32.988 UVT & Inferior & 44.769 UVT \\
\hline Pequeña empresa & $\begin{array}{l}\text { Desde } \\
\text { Hasta }\end{array}$ & $\begin{array}{l}23.563 \text { UVT } \\
204.995 \text { UVT }\end{array}$ & $\begin{array}{l}\text { Desde } \\
\text { Hasta }\end{array}$ & $\begin{array}{l}32.988 \text { UVT } \\
131.951 \text { UVT }\end{array}$ & $\begin{array}{l}\text { Desde } \\
\text { Hasta }\end{array}$ & $\begin{array}{l}44.769 \text { UVT } \\
431.196 \text { UVT }\end{array}$ \\
\hline \multirow[t]{3}{*}{ Mediana empresa } & $\begin{array}{l}\text { Desde } \\
\text { Hasta }\end{array}$ & $\begin{array}{l}204.995 \text { UVT } \\
1.736 .565 \text { UVT }\end{array}$ & $\begin{array}{l}\text { Desde } \\
\text { Hasta }\end{array}$ & $\begin{array}{l}131.951 \text { UVT } \\
483.034 \text { UVT }\end{array}$ & $\begin{array}{l}\text { Desde } \\
\text { Hasta }\end{array}$ & $\begin{array}{l}431.196 \text { UVT } \\
2.160 .692 \text { UVT }\end{array}$ \\
\hline & \multicolumn{6}{|c|}{ De ingresos ordinarios de operación (todos los ingresos excepto los financieros) } \\
\hline & UVT 2019 & 4.270 & & & & \\
\hline
\end{tabular}

Fuente: elaboración propia a partir del Decreto 1074 de 2015.

Este plazo va desde el 09 de noviembre hasta el 07 de diciembre de 2020.

Por último, los decretos 435 del 19 de marzo y 520 del 06 de abril de 2020 ampliaron el plazo para la presentación y el pago de la declaración de activos en el exterior del año gravable 2019, así:

- Grandes contribuyentes desde el 09 de junio hasta el 24 de junio.

- Personas jurídicas desde el 01 de junio hasta el 01 de julio.

Esta modificación de plazos da un alivio de caja a las empresas de mayor contextura prorrogando el pago de sus impuestos por aproximadamente 1 mes, y a las empresas pequeñas o denominadas en Colombia como Mipymes este apalancamiento de liquidez se le otorga por el término de 6 meses, subrogando así en parte la falta de percepción de ingresos para cubrir sus costos fijos por el cierre de la economía; igualmente, se facilita el 
cumplimiento de las obligaciones tributarias ya que la presentación de la declaración se traslada a la última fecha de pago y no como habitualmente se realiza que es al inicio del pago de las cuotas.

\section{B. Modificación y ampliación del plazo para la presentación de la información exógena, año gravable 2019}

Con las Resoluciones 27 del 25 de marzo y 46 del 13 de mayo de 2020, de la Dirección de Impuestos y Aduanas Nacionales (DIAN), se amplía el plazo para presentar la información exógena, así:

- Grandes contribuyentes desde el 09 de junio hasta el 24 de junio.

- Personas jurídicas desde el 01 de junio hasta el 01 de julio.

Lo anterior a fin de facilitar el cumplimiento de las obligaciones tributarias ya que se considera que el alistamiento de dicha información resulta engorroso en virtud de las disposiciones sanitarias adoptadas, como el aislamiento obligatorio que lleva al trabajo en casa.

\section{Suspensión de términos}

El Decreto 491 del 28 de marzo de 2020 y las Resoluciones 22 del 18 de marzo, 30 del 29 de marzo y 31 del 03 de abril de 2020, de la DiAN, suspenden los términos de las actuaciones administrativas y jurisdiccionales en sede administrativa durante la vigencia de la emergencia sanitaria inicialmente declarada hasta el 31 de mayo de 2020, según la Resolución 385 del 12 de marzo de 2020 del Ministerio de Salud y prorrogada hasta el 31 de agosto de 2020 con la Resolución 844 del 26 de mayo de 2020.

Esta suspensión comprende los términos de caducidad, prescripción o firmeza previstos en la legislación tributaria y no aplica para el cumplimiento de las obligaciones de presentar y pagar las declaraciones tributarias, los procesos de devoluciones, compensaciones, facilidades de pago, gestión de títulos judiciales y solicitudes de desembargo.

Estos mandatos buscan brindar seguridad jurídica al administrado y asegurar el debido proceso en el curso de las investigaciones y los procesos fiscales ejecutados por la Administración Tributaria.

\section{Medidas referentes a devoluciones}

\section{A. Devoluciones abreviadas y automáticas}

Con el Decreto 535 del 10 de abril de 2020, y la Circular Interna DIAN 5, del 16 de abril de 2020, se reglamentó el procedimiento de devoluciones abreviadas y automáticas de los saldos a favor del impuesto sobre la renta y del impuesto sobre las ventas para los 
contribuyentes clasificados de bajo riesgo, para que en el término de vigencia de la emergencia sanitaria este procedimiento sea más simple y expedito, de esta forma se redujo el término de devolución a 15 días, suprimiendo requisitos en su trámite como es el listado de costos y deducciones, y omitiendo el requisito previsto en el parágrafo 5 del artículo 855 del Estatuto Tributario de soportar los costos y gastos e IVA descontable en un $85 \%$ con factura electrónica; asimismo, se implementó la radicación de la solicitud a través del sistema informático de devoluciones para los contribuyentes que poseen firma digital, y por correo electrónico para quienes carecen de este mecanismo, la fiscalización realizada a estas solicitudes se determinó llevarla a cabo posterior al levantamiento de la vigencia de la emergencia sanitaria.

Esta norma busca inyectar liquidez a las empresas y personas naturales que han visto mermados sus ingresos por causa de las medidas sanitarias adoptadas para evitar la propagación de la pandemia del covid-19. Esta regulación de las devoluciones fue declarada inconstitucional por la Corte Constitucional colombiana a principios de septiembre de 2020 .

\section{Medidas referentes al cobro de impuestos}

\section{A. Facilidades de pago abreviadas}

Por medio del Decreto 688 del 22 de mayo de 2020 se reglamentó el procedimiento de facilidades de pago abreviadas sobre los impuestos adeudados de las declaraciones presentadas en el periodo comprendido entre el 01 de abril de 2020 y el 31 de julio de 2020 , con las cuales la obligación se podrá diferir hasta en 12 cuotas mensuales sin necesidad de garantía real, y serán estudiadas y aprobadas en un término no superior a 15 días, estas facilidades podrán ser solicitadas hasta el 06 de agosto de 2020.

Esta disposición busca financiar el pago de los impuestos que por falta de liquidez no han podido ser cubiertos durante este periodo en el cual se ha paralizado la economía, y fomentar la cultura del cumplimiento y el pago.

\section{B. Reducción tasas de interés moratorio}

Se reduce la tasa de interés moratorio sobre los impuestos adeudados, de la tasa de interés de usura a la tasa de interés bancario corriente para crédito de consumo ordinario hasta el 30 de noviembre de 2020, conforme lo preceptuado en el Decreto 688 del 22 de mayo de 2020.

Así se abarata el costo del endeudamiento por impuestos y se intensifica la cultura del pago, mejorando la liquidez de las empresas y personas naturales que se han visto golpeadas con las medidas sanitarias adoptadas para evitar la propagación del covid-19. 


\section{Control y fiscalización}

Cada una de las medidas adoptadas para la exención, exclusión, no cobro de impuestos, posee una disposición de control y fiscalización posterior a la terminación de la vigencia de la emergencia sanitaria, con la cual se busca verificar que dichos alivios se hayan aplicado de forma correcta y destinado para los fines propuestos.

Igualmente, de acuerdo a lo registrado en la Resolución 31 del 03 de abril de 2020 de la DIAN, se determinó que si bien los términos de las actuaciones administrativas y jurisdiccionales en sede administrativa fueron suspendidos, las actividad administrativa ejecutada por la Administración Tributaria no se suspende y debe continuar, por ello la fiscalización continúa desde escritorio, con el análisis de la información endógena y exógena que posee la Administración Tributaria y el cruce de información con el administrado y los terceros involucrados realizada a través de medios electrónicos, en virtud del procedimiento de notificación electrónica adoptado conforme la Resolución 38 del 05 de mayo de 2020 de la DIAN.

Estas disposiciones buscan disminuir los riesgos de prescripciones una vez levantada la suspensión de términos posterior a la emergencia sanitaria, y asegurar el debido proceso al administrado.

\section{Recaudo e ingresos tributarios}

\section{A. Exenciones de impuestos}

1. IMPUESTO SOBRE LAS VENTAS - IVA

\subsection{Artículos e implementos necesarios para la prevención, el diagnóstico y tratamiento del covid-19}

A fin de aliviar la carga tributaria de algunos artículos e implementos necesarios para la prevención, el diagnóstico y tratamiento del covid-19, conforme los decretos 438 del 19 de marzo y 551 del 15 de abril de 2020, se declaran exentos del impuesto sobre las ventas los siguientes bienes, por el término que dure la emergencia económica prevista en el Decreto 417 del 17 de marzo de 2020, y la emergencia sanitaria declarada según Resolución 385 del 12 de marzo de 2020 del Ministerio de Salud, prorrogada de acuerdo con la Resolución 844 del 26 de mayo de 2020, con vigencia hasta el 31 de agosto de 2020 (tabla 2). 


\section{TABLA 2. BIENES EXENTOS PARA ATENDER EL COVID-19}

\begin{tabular}{|c|c|c|c|c|c|}
\hline $\begin{array}{l}\text { Decreto } 438 / 2020 \\
\text { Exentos por el término de } \\
\text { la emergencia económica } \\
\text { (Decreto } 417 \text { de 2020) }\end{array}$ & \multicolumn{5}{|c|}{$\begin{array}{c}\text { Decreto 551/2020 } \\
\text { Exentos por la vigencia de la emergencia sanitaria (Resolución 385/2020 } \\
\text { Minsalud - Hasta } 31 \text { de mayo de 2020, prorrogada por Resolución 844/2020 } \\
\text { Minsalud - Hasta 31 de agosto de 2020) }\end{array}$} \\
\hline \multirow[b]{2}{*}{ Aspirador de secreciones } & $\begin{array}{l}\text { Agujas } \\
\text { hipodérmicas }\end{array}$ & Centrífugas & Gel conductor & \begin{tabular}{|l|}
$\begin{array}{l}\text { Papel grado } \\
\text { médico }\end{array}$ \\
\end{tabular} & \begin{tabular}{|l|}
$\begin{array}{l}\text { Ventilador de } \\
\text { transporte }\end{array}$ \\
\end{tabular} \\
\hline & $\begin{array}{l}\text { Alcohol etílico } \\
\text { + glicerina } \\
\text { solución tópica } \\
96 \%+4 \%\end{array}$ & $\begin{array}{l}\text { Cinta adhe- } \\
\text { siva de papel } \\
\text { microporoso }\end{array}$ & $\begin{array}{l}\text { Gel para } \\
\text { electrodos }\end{array}$ & $\begin{array}{l}\text { Pinza de } \\
\text { maguil }\end{array}$ & $\begin{array}{l}\text { Ventilador o } \\
\text { respirador de } \\
\text { uso domiciliario }\end{array}$ \\
\hline \multirow[b]{2}{*}{ Bala de oxígeno } & $\begin{array}{l}\text { Alcohol etílico } \\
+ \text { mentol loción } \\
70 \%+0,39 \% \\
\end{array}$ & $\begin{array}{l}\text { Colchón } \\
\text { antiescaras }\end{array}$ & $\begin{array}{l}\text { Geles } \\
\text { antibacteriales }\end{array}$ & Pleurovac & $\begin{array}{l}\text { Ventilador } \\
\text { o respirador } \\
\text { hospitalario } \\
\end{array}$ \\
\hline & $\begin{array}{l}\text { Alcohol etílico } \\
+ \text { mentol loción } \\
70 \%+0.5 \%\end{array}$ & Compresas & Glucómetro & $\begin{array}{l}\text { Procesadores } \\
\text { de muestras } \\
\text { de biología } \\
\text { molecular }\end{array}$ & $\begin{array}{l}\text { Videolaringos- } \\
\text { copio }\end{array}$ \\
\hline \multirow[b]{2}{*}{ Báscula pesa bebés } & $\begin{array}{l}\text { Alcohol etílico } \\
\text { gel } 63 \% 65 \%\end{array}$ & $\begin{array}{l}\text { Concentrador } \\
\text { de oxígeno }\end{array}$ & Grúas & $\begin{array}{l}\text { Productos } \\
\text { lava vajillas }\end{array}$ & \multirow{4}{*}{$\begin{array}{l}\text { Accesorios para } \\
\text { garantizar em- } \\
\text { paque cerrado } \\
\text { y transporte de } \\
\text { los elemen- } \\
\text { tos sucios y } \\
\text { limpios, como } \\
\text { compreseros, } \\
\text { vehículos para } \\
\text { la recolección } \\
\text { interna de } \\
\text { residuos, instru- } \\
\text { mental, canecas } \\
\text { de residuos, } \\
\text { entre otros. }\end{array}$} \\
\hline & $\begin{array}{l}\text { Alcohol etílico } \\
\text { solución } 70 \%\end{array}$ & $\begin{array}{l}\text { Concentrado- } \\
\text { res de oxígeno }\end{array}$ & $\begin{array}{l}\text { Guantes de lá- } \\
\text { tex y de nitrilo }\end{array}$ & $\begin{array}{l}\text { Productos } \\
\text { para desin- } \\
\text { fección de } \\
\text { dispositivos } \\
\text { médicos } \\
\end{array}$ & \\
\hline \multirow{2}{*}{ Bomba de infusión } & $\begin{array}{l}\text { Alcohol etílico } \\
\text { solución tópica } \\
96^{\circ} 72,9 \mathrm{mi} \\
/ 100 \mathrm{mi}\end{array}$ & & $\begin{array}{l}\text { Guantes } \\
\text { estériles }\end{array}$ & Prong nasal & \\
\hline & $\begin{array}{l}\text { Alcohol isopro- } \\
\text { pilico + yodo } \\
\text { loción } 72 \%+ \\
7.5 \%\end{array}$ & Desfibrilador & $\begin{array}{l}\text { Hisopos } \\
\text { con tubo de } \\
\text { transporte }\end{array}$ & $\begin{array}{l}\text { Protector fa- } \\
\text { cial: caretas o } \\
\text { visores }\end{array}$ & \\
\hline \multirow[t]{2}{*}{ Cama hospitalaria } & $\begin{array}{l}\text { Alcohol iso- } \\
\text { propílico + } \\
\text { yodopovidona } \\
\text { loción } 72 \%+ \\
7.5 \%\end{array}$ & Desinfectantes & $\begin{array}{l}\text { Incentivo } \\
\text { respiratorio }\end{array}$ & Pulsoxímetro & \multirow{2}{*}{$\begin{array}{l}\text { Alcohol etílico } \\
\text { + clorhexidi- } \\
\text { na glucona- } \\
\text { to solución } \\
\text { tópica } 76,5 \mathrm{~mL} \\
+0,45 \mathrm{~mL} \\
/ 100 \mathrm{~mL}\end{array}$} \\
\hline & $\begin{array}{l}\text { Alcohol isopro- } \\
\text { pílico al } 99 \% \\
\text { solución tópica } \\
63 \mathrm{~g} / 100 \mathrm{~mL}\end{array}$ & $\begin{array}{l}\text { Detergentes } \\
\text { para lavado de } \\
\text { ropa }\end{array}$ & Incubadora & $\begin{array}{l}\text { Rayos X } \\
\text { Arco en C }\end{array}$ & \\
\hline \multirow[t]{2}{*}{ Cama hospitalaria pediátrica } & Algodón & $\begin{array}{l}\text { Dispositivos de } \\
\text { bioseguridad } \\
\text { para traslado } \\
\text { de pacientes } \\
\end{array}$ & \begin{tabular}{|l} 
Indicadores \\
biológicos de \\
esterilización
\end{tabular} & $\begin{array}{l}\text { Rayos X } \\
\text { portátil }\end{array}$ & \multirow{2}{*}{$\begin{array}{l}\text { Alcohol Etílico } \\
\text { + Clorhexidi- } \\
\text { na Gluconato } \\
\text { Solución tópi- } \\
\text { ca70\%+1\% } \\
(\mathrm{PA} /)\end{array}$} \\
\hline & $\begin{array}{l}\text { Aplicadores } \\
\text { con punta de } \\
\text { algodón }\end{array}$ & $\begin{array}{l}\text { Dispositivos de } \\
\text { fijación de ac- } \\
\text { ceso vascular }\end{array}$ & Inhalo-cámaras & $\begin{array}{l}\text { Regulador } \\
\text { para gases } \\
\text { medicinales }\end{array}$ & \\
\hline
\end{tabular}




\begin{tabular}{|c|c|c|c|c|c|}
\hline $\begin{array}{l}\text { Decreto } 438 / 2020 \\
\text { Exentos por el término de } \\
\text { la emergencia económica } \\
\text { (Decreto } 417 \text { de 2020) } \\
\end{array}$ & \multicolumn{5}{|c|}{$\begin{array}{c}\text { Decreto 551/2020 } \\
\text { Exentos por la vigencia de la emergencia sanitaria (Resolución 385/2020 } \\
\text { Minsalud - Hasta } 31 \text { de mayo de } 2020 \text {, prorrogada por Resolución } 844 / 2020 \\
\text { Minsalud - Hasta } 31 \text { de agosto de 2020) }\end{array}$} \\
\hline \multirow[t]{2}{*}{ Cámara cefálica } & $\begin{array}{l}\text { Apósito } \\
\text { adhesivo }\end{array}$ & Doppler fetal & \begin{tabular}{|l} 
Intensificador \\
de imagen \\
portátil
\end{tabular} & $\begin{array}{l}\text { Rodillos para } \\
\text { traslado }\end{array}$ & \multirow{2}{*}{$\begin{array}{l}\text { Alcohol Etílico } \\
+ \text { Clorhexidi- } \\
\text { na Gluconato } \\
\text { Solución tópi- } \\
\text { ca70\% } \% 2 \%\end{array}$} \\
\hline & Apósitos & Ecocardiógrafo & Jabones & $\begin{array}{l}\text { Sensores de } \\
\text { EKG }\end{array}$ & \\
\hline \multirow[t]{2}{*}{ Concentrador de oxígeno } & $\begin{array}{l}\text { Autoclaves, } \\
\text { esterilizadores } \\
\text { y accesorios }\end{array}$ & Ecógrafo & Jeringas & $\begin{array}{l}\text { Sensores de } \\
\text { saturación de } \\
\text { oxígeno }\end{array}$ & \multirow{2}{*}{$\begin{array}{l}\text { Alcohol Etílico } \\
+ \text { Alcohol } \\
\text { Isopropílico } \\
\text { Gel } 63 \mathrm{~g}+\text { C. S. } \\
\text { P } 100\end{array}$} \\
\hline & Bala de oxígeno & $\begin{array}{l}\text { Electrocardió- } \\
\text { grafo }\end{array}$ & $\begin{array}{l}\text { Jeringas de } \\
\text { infusión }\end{array}$ & $\begin{array}{l}\text { Sensores de } \\
\text { temperatura }\end{array}$ & \\
\hline \multirow[b]{2}{*}{ Desfibrilador } & $\begin{array}{l}\text { Báscula pesa } \\
\text { bebés }\end{array}$ & $\begin{array}{l}\text { Electrodos de } \\
\text { ventosa }\end{array}$ & $\begin{array}{l}\text { Kit de } \\
\text { entubación }\end{array}$ & \begin{tabular}{|l|} 
Sillas de \\
ruedas
\end{tabular} & \multirow{2}{*}{$\begin{array}{l}\text { Circuitos y } \\
\text { aditamentos } \\
\text { de ventilación } \\
\text { (Sensores, } \\
\text { Filtros, entre } \\
\text { otros) }\end{array}$} \\
\hline & Blanketrol & $\begin{array}{l}\text { Electrodos } \\
\text { desechables }\end{array}$ & $\begin{array}{l}\text { Lámpara de } \\
\text { calor radiante }\end{array}$ & $\begin{array}{l}\text { Soluciones } \\
\text { antibacte- } \\
\text { riales }\end{array}$ & \\
\hline \multirow{2}{*}{ Electrocardiógrafo } & $\begin{array}{l}\text { Bolsa para } \\
\text { nutrición } \\
\text { parenteral }\end{array}$ & $\begin{array}{l}\text { Electrodos pa- } \\
\text { ra Cardio-des- } \\
\text { fibrilador }\end{array}$ & $\begin{array}{l}\text { Lámpara de } \\
\text { fototerapia }\end{array}$ & $\begin{array}{l}\text { Sonda de } \\
\text { aspiración } \\
\text {-nelaton de } \\
\text { diferentes } \\
\text { medidas }\end{array}$ & \multirow{2}{*}{$\begin{array}{l}\text { Clorhexidina } \\
\text { Gluconato + } \\
\text { Alcohol Isopro- } \\
\text { pilico Solución } \\
\text { tópica } 2 \%+ \\
70 \%, 4 \%+ \\
70 \%\end{array}$} \\
\hline & $\begin{array}{l}\text { Bolsas de } \\
\text { Ostomía }\end{array}$ & $\begin{array}{l}\text { Electrodos pa- } \\
\text { ra desfibrilador } \\
\text { o marcapasos }\end{array}$ & $\begin{array}{l}\text { Laringoscopio } \\
\text { de hojas rectas } \\
\text { y curvas (niños } \\
\text { y adultos) }\end{array}$ & $\begin{array}{l}\text { Sonda na- } \\
\text { sogástrica, } \\
\text { orogástrica y } \\
\text { gastro-yeyu- } \\
\text { nal }\end{array}$ & \\
\hline \multirow[b]{2}{*}{$\begin{array}{l}\text { Equipo de órganos de los } \\
\text { sentidos }\end{array}$} & $\begin{array}{l}\text { Bolsas } \\
\text { mortuorias }\end{array}$ & $\begin{array}{l}\text { Electrodos } \\
\text { superficiales }\end{array}$ & $\begin{array}{l}\text { Limpiadores } \\
\text { de superficies }\end{array}$ & $\begin{array}{l}\text { Sondas de } \\
\text { succión } \\
\text { abierta o } \\
\text { cerrada }\end{array}$ & \multirow{2}{*}{$\begin{array}{l}\text { Clorhexidina } \\
\text { Gluconato } \\
\text { Solución tópica } \\
0.07 \% 0.08 \% \\
0.45 \% 2 \% 1 \%\end{array}$} \\
\hline & $\begin{array}{l}\text { Bolsas para } \\
\text { recolección de } \\
\text { orina }\end{array}$ & $\begin{array}{l}\text { Equipo de des- } \\
\text { infección por } \\
\text { ultravioleta }\end{array}$ & $\begin{array}{l}\text { Manómetro } \\
\text { para oxígeno y } \\
\text { vacío }\end{array}$ & $\begin{array}{l}\text { Sondas } \\
\text { urinarias } \\
\text { de diferen- } \\
\text { tes clases y } \\
\text { medidas }\end{array}$ & \\
\hline \multirow[t]{2}{*}{ Equipo de rayos $\mathrm{X}$ portátil } & $\begin{array}{l}\text { Bolsas para } \\
\text { sangre }\end{array}$ & $\begin{array}{l}\text { Equipo de } \\
\text { gases arteriales } \\
\text { y venosos }\end{array}$ & $\begin{array}{l}\text { Mantas para } \\
\text { calentamiento }\end{array}$ & $\begin{array}{l}\text { Succio- } \\
\text { nador o } \\
\text { aspirador de } \\
\text { secreciones }\end{array}$ & \multirow{2}{*}{$\begin{array}{l}\text { Dispositivos } \\
\text { médicos para } \\
\text { lesiones de piel } \\
\text { por estancias } \\
\text { prolongadas }\end{array}$} \\
\hline & $\begin{array}{l}\text { Bolsas y tubos } \\
\text { para recolec- } \\
\text { ción de sangre }\end{array}$ & $\begin{array}{l}\text { Equipo de } \\
\text { órgano de los } \\
\text { sentidos }\end{array}$ & $\begin{array}{l}\text { Máquina } \\
\text { de diálisis } \\
\text { peritoneal }\end{array}$ & $\begin{array}{l}\text { Succiona- } \\
\text { dores }\end{array}$ & \\
\hline
\end{tabular}


Ana Cristina Triana Suárez

\begin{tabular}{|c|c|c|c|c|c|}
\hline $\begin{array}{l}\text { Decreto } 438 / 2020 \\
\text { Exentos por el término de } \\
\text { la emergencia económica } \\
\text { (Decreto } 417 \text { de 2020) }\end{array}$ & \multicolumn{5}{|c|}{$\begin{array}{c}\text { Decreto 551/2020 } \\
\text { Exentos por la vigencia de la emergencia sanitaria (Resolución 385/2020 } \\
\text { Minsalud - Hasta 31 de mayo de 2020, prorrogada por Resolución 844/2020 } \\
\text { Minsalud - Hasta 31 de agosto de 2020) }\end{array}$} \\
\hline \multirow{2}{*}{ Flujómetro } & $\begin{array}{l}\text { Bombas de } \\
\text { infusión y equi- } \\
\text { po bomba de } \\
\text { infusión }\end{array}$ & $\begin{array}{l}\text { Equipo de } \\
\text { órganos de los } \\
\text { sentidos }\end{array}$ & $\begin{array}{l}\text { Máquina de } \\
\text { hemodiálisis }\end{array}$ & $\begin{array}{l}\text { Sujetador } \\
\text { de tubo de } \\
\text { traqueostomía }\end{array}$ & \multirow{2}{*}{$\begin{array}{l}\text { Dispositi- } \\
\text { vos para la } \\
\text { recolección } \\
\text { de muestras y } \\
\text { fluidos, incluid } \\
\text { la trampa de } \\
\text { recolección de } \\
\text { secreciones }\end{array}$} \\
\hline & $\begin{array}{l}\text { Bombas de nu- } \\
\text { trición enteral }\end{array}$ & $\begin{array}{l}\text { Equipo de } \\
\text { plasmaféresis }\end{array}$ & $\begin{array}{l}\text { Máscara de } \\
\text { alto flujo } \\
\text { (Ventury) }\end{array}$ & $\begin{array}{l}\text { Sujetador } \\
\text { de tubo } \\
\text { endotraqueal }\end{array}$ & \\
\hline \multirow[b]{2}{*}{ Fonendoscopio } & Buretrol & $\begin{array}{l}\text { Equipo de quí- } \\
\text { mica sanguínea }\end{array}$ & $\begin{array}{l}\text { Mascarilla con } \\
\text { reservorio }\end{array}$ & Suturas & \multirow{2}{*}{$\begin{array}{l}\text { Espumas: En } \\
\text { diferentes ta- } \\
\text { maños y formas } \\
\text { (región sacra, } \\
\text { taloneras, }\end{array}$} \\
\hline & $\begin{array}{l}\text { Cama } \\
\text { hospitalaria }\end{array}$ & $\begin{array}{l}\text { Equipo de ra- } \\
\text { yos X portátil }\end{array}$ & $\begin{array}{l}\text { Mascarilla de } \\
\text { traqueostomía } \\
\text { (tienda de } \\
\text { traqueostomía) }\end{array}$ & $\begin{array}{l}\text { Suturas de } \\
\text { seda }\end{array}$ & \\
\hline \multirow[b]{2}{*}{ Glucómetro } & $\begin{array}{l}\text { Cama hospita- } \\
\text { laria pediátrica }\end{array}$ & $\begin{array}{l}\text { Equipo de } \\
\text { traqueostomía }\end{array}$ & $\begin{array}{l}\text { Mascarilla } \\
\text { laríngea }\end{array}$ & $\begin{array}{l}\text { Tablero } \\
\text { para masaje } \\
\text { cardiaco }\end{array}$ & \multirow{2}{*}{$\begin{array}{l}\text { Humidífica- } \\
\text { dor (normal, } \\
\text { jet y burbuja) } \\
\text { y filtros del } \\
\text { humidificador }\end{array}$} \\
\hline & Cámara cefálica & $\begin{array}{l}\text { Equipo para } \\
\text { desinfección } \\
\text { por ultrasonido }\end{array}$ & $\begin{array}{l}\text { Mascarilla } \\
\text { N95 y respi- } \\
\text { radores FFP2 o } \\
\text { FFP3 }\end{array}$ & $\begin{array}{l}\text { Tapabocas } \\
\text { desechables }\end{array}$ & \\
\hline \multirow[t]{2}{*}{ Incubadora } & Camas & $\begin{array}{l}\text { Equipo para } \\
\text { presión venosa } \\
\text { central }\end{array}$ & $\begin{array}{l}\text { Mascarilla } \\
\text { para nebuliza- } \\
\text { ción - micro- } \\
\text { nebulización }\end{array}$ & Tensiómetro & \multirow{2}{*}{$\begin{array}{l}\text { Neveras de } \\
\text { transporte, Pilas } \\
\text { de gel y silicona } \\
\text { para transporte }\end{array}$} \\
\hline & Camillas & $\begin{array}{l}\text { Equipo para } \\
\text { transfusión } \\
\text { sanguínea }\end{array}$ & $\begin{array}{l}\text { Mascarilla } \\
\text { quirúrgica con } \\
\text { filtro HEPA } \\
\end{array}$ & \begin{tabular}{|l} 
Tensióme- \\
tro digital y \\
manual
\end{tabular} & \\
\hline \multirow[b]{2}{*}{ Lámpara de calor radiante } & Caminadores & $\begin{array}{l}\text { Equipo para } \\
\text { venodisección }\end{array}$ & $\begin{array}{l}\text { Mascarilla } \\
\text { simple }\end{array}$ & $\begin{array}{l}\text { Termocicla- } \\
\text { dores }\end{array}$ & \multirow{3}{*}{$\begin{array}{l}\text { Monitor de } \\
\text { signos vitales } \\
\text { (Medición } \\
\text { de frecuen- } \\
\text { cia cardiaca, } \\
\text { presión arterial } \\
\text { sistólica, diastó- } \\
\text { lica y media, } \\
\text { temperatura, } \\
\text { saturación de } \\
\text { oxígeno, gasto } \\
\text { cardíaco) }\end{array}$} \\
\hline & $\begin{array}{l}\text { Cánulas de gue- } \\
\text { del o de mayo }\end{array}$ & $\begin{array}{l}\text { Equipos de } \\
\text { venoclisis }\end{array}$ & $\begin{array}{l}\text { Mascarillas } \\
\text { con filtro }\end{array}$ & $\begin{array}{l}\text { Termóme- } \\
\text { tro digital y } \\
\text { manual }\end{array}$ & \\
\hline \multirow[t]{2}{*}{ Monitor de signos vitales } & $\begin{array}{l}\text { Cánulas de } \\
\text { traqueostomía }\end{array}$ & $\begin{array}{l}\text { Equipos para } \\
\text { la apnea (CPAP } \\
\text { - BPAP) }\end{array}$ & $\begin{array}{l}\text { Mascarillas } \\
\text { para anestesia }\end{array}$ & $\begin{array}{l}\text { Tubos de } \\
\text { mediastino }\end{array}$ & \\
\hline & $\begin{array}{l}\text { Cánulas } \\
\text { laríngeas }\end{array}$ & Esparadrapo & $\begin{array}{l}\text { Mascarillas pa- } \\
\text { ra reinhalación }\end{array}$ & $\begin{array}{l}\text { Toallitas } \\
\text { húmedas }\end{array}$ & $\begin{array}{l}\text { Otro tipo de } \\
\text { catéteres de } \\
\text { acceso vascular } \\
\text { periférico y } \\
\text { central, arterial } \\
\text { y venoso }\end{array}$ \\
\hline
\end{tabular}




\begin{tabular}{|c|c|c|c|c|c|}
\hline $\begin{array}{l}\text { Decreto } 438 / 2020 \\
\text { Exentos por el término de } \\
\text { la emergencia económica } \\
\text { (Decreto } 417 \text { de 2020) } \\
\end{array}$ & \multicolumn{5}{|c|}{$\begin{array}{c}\text { Decreto 551/2020 } \\
\text { Exentos por la vigencia de la emergencia sanitaria (Resolución } 385 / 2020 \\
\text { Minsalud - Hasta } 31 \text { de mayo de } 2020 \text {, prorrogada por Resolución } 844 / 2020 \\
\text { Minsalud - Hasta } 31 \text { de agosto de 2020) }\end{array}$} \\
\hline \multirow[t]{2}{*}{ Monitor de transporte } & Cánulas nasales & Espirómetros & $\begin{array}{l}\text { Medias } \\
\text { antiembólicas }\end{array}$ & $\begin{array}{l}\text { Trajes de } \\
\text { bio-protec- } \\
\text { ción (ente- } \\
\text { rizo, blusa y } \\
\text { pantalón) }\end{array}$ & $\begin{array}{l}\text { Otro tipo de } \\
\text { catéteres de } \\
\text { acceso vascular } \\
\text { periférico y } \\
\text { central, arterial } \\
\text { y venoso }\end{array}$ \\
\hline & $\begin{array}{l}\text { Cánulas nasales } \\
\text { de alto flujo }\end{array}$ & $\begin{array}{l}\text { Estilete o guía } \\
\text { de entubación }\end{array}$ & $\begin{array}{l}\text { Monitor de } \\
\text { presión arterial }\end{array}$ & $\begin{array}{l}\text { Tubo co- } \\
\text { nector en T } \\
\text { o Y, Niple } \\
\text { conector }\end{array}$ & \multirow{4}{*}{$\begin{array}{l}\text { Protección total } \\
\text { del cuerpo: ba- } \\
\text { tas, gorros, ropa } \\
\text { quirúrgica esté- } \\
\text { ril, campos qui- } \\
\text { rúrgicos, campo } \\
\text { operatorio, sá- } \\
\text { banas, fundas, } \\
\text { traje biológi- } \\
\text { co, polainas } \\
\text { y protectores } \\
\text { metatarsales }\end{array}$} \\
\hline & $\begin{array}{l}\text { Cánulas } \\
\text { nasofaríngeas }\end{array}$ & $\begin{array}{l}\text { Extensión de } \\
\text { anestesia }\end{array}$ & $\begin{array}{l}\text { Monitor de } \\
\text { transporte }\end{array}$ & \begin{tabular}{|l|} 
Tubos \\
capilares \\
\end{tabular} & \\
\hline Nebulizador & $\begin{array}{l}\text { Cánulas } \\
\text { orofaríngeas }\end{array}$ & $\begin{array}{l}\text { Fibroscopio y } \\
\text { Fibrobroncos- } \\
\text { copio }\end{array}$ & Monitor fetal & $\begin{array}{l}\text { Tubos de } \\
\text { tórax de } \\
\text { diferentes } \\
\text { números o } \\
\text { calibres }\end{array}$ & \\
\hline \multirow{2}{*}{ Pulsoxímetro } & Capnógrafo & $\begin{array}{l}\text { Filtros de en- } \\
\text { trada y salida } \\
\text { de aire }\end{array}$ & $\begin{array}{l}\text { Nebulizador y } \\
\text { Micro-nebuli- } \\
\text { zador }\end{array}$ & $\begin{array}{l}\text { Tubos } \\
\text { heparinizados }\end{array}$ & \\
\hline & $\begin{array}{l}\text { Cardiodesfibri- } \\
\text { lador }\end{array}$ & Flujómetro & $\begin{array}{l}\text { Tubos de } \\
\text { recolección de } \\
\text { sangre }\end{array}$ & $\begin{array}{l}\text { Válvula de } \\
\text { Heimlich }\end{array}$ & \multirow{3}{*}{$\begin{array}{l}\text { Respirador } \\
\text { manual - Bolsa } \\
\text { auto-inflable } \\
\text { - Balón resu- } \\
\text { citador - Bolsa } \\
\text { de reanimación } \\
\text { (AMBU) con o } \\
\text { sin reservorio }\end{array}$} \\
\hline \multirow[t]{2}{*}{ Tensiómetro } & $\begin{array}{l}\text { Carro de paro } \\
\text { cardiaco }\end{array}$ & $\begin{array}{l}\text { Flujómetro } \\
\text { para gases } \\
\text { medicinales }\end{array}$ & $\begin{array}{l}\text { Otros dis- } \\
\text { positivos } \\
\text { médicos de } \\
\text { movilización }\end{array}$ & $\begin{array}{l}\text { Válvula } \\
\text { exploratoria }\end{array}$ & \\
\hline & $\begin{array}{l}\text { Catéter central } \\
\text { (Swanz Ganz y } \\
\text { subclavio) }\end{array}$ & Fonendoscopio & $\begin{array}{l}\text { Otros tipos de } \\
\text { cánulas }\end{array}$ & $\begin{array}{l}\text { Válvulas de } \\
\text { flujo }\end{array}$ & \\
\hline \multirow[t]{2}{*}{ Ventilador } & $\begin{array}{l}\text { Catéter perifé- } \\
\text { rico vascular e } \\
\text { intraóseo }\end{array}$ & $\begin{array}{l}\text { Gafas } \\
\text { protectoras }\end{array}$ & $\begin{array}{l}\text { Otros tipos de } \\
\text { mascarillas }\end{array}$ & Vendas & \multirow{2}{*}{$\begin{array}{l}\text { Sistema de } \\
\text { drenaje cerrado } \\
\text { para conexión a } \\
\text { tubo de tórax o } \\
\text { mediastino }\end{array}$} \\
\hline & $\begin{array}{l}\text { Celdas de } \\
\text { oxígeno }\end{array}$ & Gasas & $\begin{array}{l}\text { Otros tipos de } \\
\text { sondas }\end{array}$ & Ventilador & \\
\hline Lámpara de fototerapia & $\begin{array}{l}\text { Sistema de } \\
\text { recolección } \\
\text { de secrecio- } \\
\text { nes o fluidos } \\
\text { (caníster, re- } \\
\text { ceptal o linner) } \\
\text { con o sin gel } \\
\text { solidificante) }\end{array}$ & $\begin{array}{l}\text { Toallas y } \\
\text { pañines im- } \\
\text { pregnados con } \\
\text { clorhexidina o } \\
\text { alcohol al } 70 \%\end{array}$ & $\begin{array}{l}\text { Tubos endo- } \\
\text { traqueales y } \\
\text { nasotraqueales } \\
\text { y combitube } \\
\text { (tubo combi- } \\
\text { nado esófa- } \\
\text { go-tráquea) } \\
\text { de diferentes } \\
\text { medidas }\end{array}$ & & \\
\hline
\end{tabular}

Bienes a los que se les amplía la exención por la vigencia de la emergencia sanitaria

Fuente: elaboración propia a partir de los decretos 438 del 19 de marzo de 2020 y 551 del 15 de abril de 2020. 


\subsection{Comisiones servicios financieros}

Igualmente, se aplica exención de IVA a las comisiones por el servicio de dispersión de fondos de los recursos de los programas de apoyo económico, así:

A la población vulnerable

- Programa ingreso solidario (Decreto 518 del 28 de marzo de 2020).

- Programa apoyo económico excepcional a la población en proceso de reintegración (Decreto 570 del 15 de abril de 2020).

- Programa transferencia adicional y extraordinaria, programas familias en acción y adulto mayor (Decreto 659 del 13 de mayo de 2020).

A las empresas afectadas por la paralización de la economía:

- Programa apoyo al empleo formal (PAEF) (Decreto 639 del 08 de mayo de 2020).

\subsection{Servicios de conexión y acceso a voz e internet móvil}

De acuerdo con el Decreto 540 del 13 de abril de 2020 se fija exención de IVA por el término de 4 meses, es decir hasta el 12 de agosto de 2020, a los servicios de conexión y acceso a voz e internet móvil, cuyo valor no supere las 2 UVT (\$71.214 - UVT 2020 \$35.607), con el fin de dar mayor acceso a la conectividad digital requerida para el desarrollo de la educación y el trabajo desde casa desarrollada en virtud del aislamiento obligatorio.

\subsection{Bienes cubiertos con exención de 3 días}

Con el propósito de dar impulso a la reactivación económica conforme lo descrito en el Decreto 682 del 21 de mayo de 2020, se reglamenta la exención especial de IVA prevista en el Capítulo II, artículos 22 al 25 de la Ley 2010 de 2019 (Nueva Ley de Financiamiento), fijando 3 días sin IvA en las fechas 19 de junio de 2020, 03 de julio de 2020 y 19 de julio de 2020, en las cuales estarán exentos de IVA los siguientes bienes cubiertos (tabla 3):

\section{GRAVAMEN A LOS MOVIMIENTOS FINANCIEROS (GMF)}

Se decreta la exención del Gravamen a los movimientos financieros (GMF) para las siguientes operaciones:

- Transferencias Programa Ingreso Solidario (Decreto 518 del 28 de marzo de 2020).

- Transferencias Programa apoyo económico excepcional a la población en proceso de reintegración (Decreto 570 del 15 de abril de 2020). 
Tabla 3. Bienes Cubiertos EXenCión iva 3 días

\begin{tabular}{|l|l|}
\hline \multicolumn{1}{|c|}{ Bien } & \multicolumn{1}{c|}{ Valor máximo por unidad } \\
\hline Vestuario & Menor o igual a 20 UVT sin IVA $(\$ 712.140)$ \\
\hline Complemento vestuario & Menor o igual a 20 UVT sin IVA $(\$ 712.140)$ \\
\hline Electrodomésticos & Menor o igual a 80 UVT sin IVA $(\$ 2.848 .560)$ \\
\hline Elementos deportivos & Menor o igual a 80 UVT sin IVA $(\$ 2.848 .560)$ \\
\hline Juguetes y juegos & Menor o igual a 10 UVT sin IVA $(\$ 356.070)$ \\
\hline Útiles escolares & Menor o igual a 5 UVT sin IVA $\$$ 178.035) \\
\hline Bienes e insumos sector agropecuario & Menor o igual a 80 UVT sin IVA $(\$ 2.848 .560)$ \\
\hline UVT 2020 \$35.607 & \\
\hline
\end{tabular}

Fuente: elaboración propia a partir del Decreto 682 del 21 de mayo de 2020.

- Transferencias Programa transferencia adicional y extraordinaria Programa Familias en Acción y adulto mayor (Decreto 659 del 13 de mayo de 2020).

- Transferencias programa apoyo al empleo formal (PAEF) (Decreto 639 del 08 de mayo de 2020).

- Retiros realizados por el término de vigencia de la emergencia sanitaria de las cuentas de uso exclusivo para el manejo de recursos destinados a la población vulnerable por las entidades sin ánimo de lucro (ESAL), pertenecientes al régimen tributario especial (RTE) (Decreto 530 del 08 de abril de 2020).

- Desembolso operaciones de crédito realizadas entre Findeter y las Empresas de servicio público (ESP) (Decreto 581 del 15 de abril de 2020).

\section{B. Exclusión de impuestos}

\section{IMPUESTO SOBRE LAS VENTAS}

\subsection{Comisiones servicios otorgamiento de garantías y de créditos}

Se adopta la exclusión del impuesto al valor agregado (IVA), o impuesto sobre las ventas para las comisiones originadas en el servicio de otorgamiento de garantías y de créditos realizadas por:

- Fondo Nacional de Garantías (FNG) (Decreto 492 del 28 marzo de 2020).

- Fondo Agropecuario de Garantías (FAG) (Decreto 573 del 15 de abril de 2020).

- FINDETER a las Empresas de Servicios Públicos (ESP) (Decreto 581 del 15 de abril de 2020). 


\subsection{Comisiones locales comerciales}

De igual forma, conforme lo previsto en el Decreto 682 del 21 de mayo de 2020, con el fin de aliviar la carga tributaria de los sectores económicos mayormente afectados por las medidas sanitarias adoptadas, se excluye del IVA hasta el 31 de julio de 2020 el arrendamiento de los locales comercial que hayan cerrado al público total o parcialmente por más de dos semanas.

\section{RETENCIÓN EN LA FUENTE A TíTULO DE IMPUESTO SOBRE LA RENTA}

Mediante Decreto 560 del 15 de abril de 2020, se excluyen de retención en la fuente a título de impuesto sobre la renta hasta el 31 de diciembre de 2020, las empresas admitidas en procesos de reorganización empresarial o que estén ejecutando acuerdos de reorganización celebrados conforme a la Ley de Insolvencia (Ley 1116 de 2006).

\section{Reducción de impuestos}

\section{IMPUESTO SOBRE LAS VENTAS}

\subsection{Gasolina de aviación y servicios de transporte aéreo de pasajeros}

Se reduce la tarifa del IVA aplicable a la comercialización de la gasolina de aviación y la prestación de servicios de transporte aéreo de pasajeros, a la tarifa especial del $5 \%$ hasta el 31 de diciembre de 2020 conforme lo previsto en el Decreto 575 del 15 abril de 2020.

\subsection{Donaciones}

De acuerdo con lo establecido en el Decreto 530 del 08 de abril de 2020, se exceptúa el pago de IVA en la transferencia a título gratuito (donación) de los siguientes bienes:

- Bienes para consumo humano o animal.

- Vestuario.

- Elementos de aseo.

- Medicamentos para uso humano o veterinario.

- Materiales de construcción.

- Dispositivos médicos.

Siempre y cuando estos se destinen única y exclusivamente a la atención de las causas de la emergencia sanitaria y económica generada por el covid-19. 


\section{RETENCIÓN EN LA FUENTE}

Se reduce al $4 \%$ la tarifa de retención en la fuente aplicable sobre los pagos o abonos en cuenta de comisiones por servicios de garantías otorgadas por:

- Fondo Nacional de Garantías (FNG) (Decreto 492 del 28 marzo de 2020).

- Fondo Agropecuario de Garantías (FAG) (Decreto 573 del 15 de abril de 2020).

\section{Impuesto Nacional al Consumo (INC)}

Se disminuye a $0 \%$ hasta el 31 de diciembre de 2020, la tarifa del INC del servicio de expendio de comidas y bebidas.

\section{Compensación impuestos población vulnerable}

Por medio del Decreto 419 del 18 de mayo de 2020 y la Resolución 1058 del 27 de marzo de 2020, del Departamento Nacional de Planeación (DNP), se reglamenta la compensación del IVA pagado por la población más vulnerable previsto como mecanismo de equidad y progresividad del tributo en el artículo 21 de la Ley 2010 de 2019, fijando la devolución de 2,1065 uVT (\$75.000 - UVT $2020 \$ 35.607$ ) a los hogares en situación de pobreza y extrema pobreza inscritos en el Sisben III y IV.

\section{E. Modificación beneficios tributarios}

Por medio del Decreto 575 del 15 de abril de 2020, se modificaron las condiciones para acceder al beneficio tributario de reducción de tarifa del impuesto de renta y no pago del impuesto al patrimonio fijado por el artículo 235-3 para las megainversiones a fin de brindar mayor inclusión a este régimen para las sociedades del sector aeronáutico nacional duramente golpeadas como consecuencia de las medidas sanitarias adoptadas por el covid-19, para las cuales se reduce a 2.000.000 UVT (\$71.214.000.000 - UVT $2020 \$ 35.607)$ el valor de la inversión requerida.

\section{F. Nuevos impuestos}

De acuerdo con el Decreto 568 del 15 de abril de 2020, se crea el impuesto solidario con el fin de generar mayores ingresos tributarios que suplan la disminución del recaudo originado por las distintas medidas tomadas para aliviar la carga tributaria de los sectores económicos mayormente golpeados por las medidas sanitarias adoptadas para frenar la propagación y el contagio del covid-19 y cubrir el gasto público social que se requiere para atender a la población vulnerable. 
Este impuesto se genera sobre los pagos o abonos en cuenta superiores a $\$ 10.000 .000$, realizados a los prestadores de servicios al Estado, servidores públicos y beneficiarios de magapensiones, que no pertenezcan al sector salud y la fuerza pública; la tarifa será escalonada del 15 al $20 \%$, según el valor del pago o abono en cuenta realizado como se muestra en la tabla 4.

\section{TABla 4. TARIFA IMPUESTO SOLIDARIO}

\begin{tabular}{|l|l|c|}
\hline \multicolumn{2}{|c|}{ Valor pago o abono en cuenta } & Tarifa \\
\hline Desde $\$ 10.000 .000$ & Hasta $\$ 12.500 .000$ & $15 \%$ \\
\hline Desde $\$ 12.500 .000$ & Hasta \$15.000.000 & $16 \%$ \\
\hline Desde $\$ 15.000 .000$ & Hasta \$20.000.000 & $17 \%$ \\
\hline Desde $\$ 20.000 .000$ & En adelante & $20 \%$ \\
\hline
\end{tabular}

Fuente: elaboración propia a partir del Decreto 568 del 15 de abril de 2020.

El mecanismo de recaudo será a través de retención en la fuente y su vigencia será de 3 meses durante el periodo comprendido entre el 01 de mayo de 2020 y el 31 de julio de 2020 .

\section{Medidas referentes al apoyo informático para facilitación de trámites y su cumplimiento}

\section{A. Notificación electrónica}

Conforme al Decreto 491 del 28 de marzo de 2020, de acuerdo con la Resolución 038 del 30 de abril de la DIAN, se implementa la notificación electrónica prevista en el artículo 566-1 del Estatuto Tributario como mecanismo preferente de notificación, la cual entrará en vigor de forma escalonada para los diferentes procesos que ejecuta la Administración Tributaria.

\section{B. Servicios virtuales}

La DIAN continúa con la prestación de los servicios virtuales para la realización de trámites, entre los que se pueden listar:

- Inscripción al Registro Único Tributario (RUT) para no responsables del IVA.

- Actualización del RUT.

- Presentación y pago declaraciones tributarias.

- Autorización, habilitación e inhabilitaciones de numeración de facturación.

- Consulta de información exógena.

- Gestión de Peticiones, Quejas, Reclamos y Sugerencias (PQRS).

- Consultas tributarias aduaneras y cambiarias. 
Igualmente, ante los desafíos planteados por el covid-19, se habilita el Servicio Informático para la radicación de las solicitudes de devolución y compensación; asimismo, se dispone el punto de contacto virtual mediante el cual se reciben los trámites y soportes a través de correo electrónico y se remite el resultado del respectivo trámite el mismo día.

\section{La factura electrónica}

Mediante Resolución 042 del 05 de marzo de 2020 se desarrolla la implementación de la factura electrónica como sistema de facturación preferente en Colombia, y herramienta esencial de control y fiscalización, la cual se implementará de forma escalonada durante el periodo comprendido entre el 15 de junio de 2020 y el 01 de noviembre de 2020, el cual se amplió a estas fechas en atención al decaimiento de la Ley 1943 de 2019 y la respectiva normatividad reglamentaria.

Sin duda, el mecanismo de factura electrónica concebido por la Administración Tributaria colombiana resulta ser el eje fundamental para el control y la fiscalización de la tributación en el país, ya que mediante este, siguiendo el modelo mexicano añadido por el modelo peruano respecto a la forma de validación previa, se podrá establecer la categorización de contribuyentes respecto al riesgo de evasión que poseen y trascender de la evaluación de riesgo de evasión por actividades que sesgan el control y la fiscalización en virtud de la participación individual de los evasores; asimismo, permitirá tener información en tiempo real para el control de costos y deducciones, y mitigar el gran flagelo que aqueja al sistema tributario colombiano como es el soporte de costos, deducciones e impuestos descontables con facturas falsas o ficticias.

\section{Conclusiones}

Debido a las diferentes medidas de facilitación, apalancamiento y alivio adoptadas para enfrentar las consecuencias de la emergencia sanitaria generada por el covid-19, el recaudo tributario para el año gravable 2020 disminuirá en 2,21 billones, de acuerdo con las cifras presentadas por el Ministerio de Hacienda y Crédito Público, en el Especial televisivo Prevención y acción del 27 de mayo de 2020 (Ministerio de Hacienda y Crédito Público, 2020); igualmente, la Administración Tributaria estima que la paralización de la economía como consecuencia de las medidas sanitarias adoptadas generará una disminución del recaudo en el año 2020 aproximadamente entre 15 y 20 billones de pesos, de acuerdo con lo expresado por el director general de la DIAN en la intervención realizada en el Especial televisivo Prevención y acción.

De igual forma, se puede concluir que la pandemia covid-19, impulsó el mejoramiento del apoyo informático electrónico y la simplificación de algunos procesos ejecutados por la Administración Tributaria como son las devoluciones y compensaciones de los saldos a favor, las facilidades de pago, el proceso de notificaciones y el impulso definitivo de la factura electrónica. 
Por último, vale la pena reflexionar sobre las medidas adoptadas, que dejan de manifiesto la inequidad y regresividad perenne en el sistema tributario colombiano, así como la complejidad de este, que junto con la operatividad de la Administración Tributaria dificultan el cumplimiento, generan inestabilidad jurídica y desestiman la tributación.

\section{Referencias}

Dirección de Impuestos y Aduanas Nacionales (DIAN) (2020). Circular 5 de 16 de abril de 2020. https://www.dian.gov.co/normatividad/Normatividad/Circular\%20 000005\%20de\%2016-04-2020.pdf

Ministerio de Hacienda y Crédito Público (2020, 27 de mayo). Viceministro general en Especial televisivo Prevención y acción [video]. YouTube.

\section{Normatividad}

Departamento Nacional de Planeación (DPN) (2020). Resolución 1058 de 27 de marzo de 2020. https://devolucioniva.dnp.gov.co/Documentos/Resolucion\%201058\%20 de\%202020.pdf

Dirección de Impuestos y Aduanas Nacionales (DIAN) (2020). Resolución 27 de 5 de marzo de 2020. https://www.dian.gov.co/normatividad/Normatividad/Resoluci\%C3\%B3n\%20000027\%20de\%2025-03-2020.pdf

Dirección de Impuestos y Aduanas Nacionales (DIAN) (2020). Resolución 46 de 7 de mayo de 2020. https://www.dian.gov.co/normatividad/Normatividad/Resoluci\%C3\%B3n\%20000046\%20de\%2007-05-2020.pdf

Dirección de Impuestos y Aduanas Nacionales (DIAN) (2020). Resolución 30 de 29 de marzo de 2020. https://www.dian.gov.co/normatividad/Normatividad/Resoluci\%C3\%B3n\%20000030\%20de\%2029-03-2020.pdf

Dirección de Impuestos y Aduanas Nacionales (DIAN) (2020). Resolución 31 de 3 de abril de 2020. https://www.dian.gov.co/normatividad/Normatividad/Resoluci\%C3\%B3n\%20000031\%20de\%2003-04-2020.pdf

Dirección de Impuestos y Aduanas Nacionales (DIAN) (2020). Resolución 42 de 5 de mayo de 2020. https:/www.dian.gov.co/normatividad/Normatividad/Resoluci\%C3\%B3n\%20000042\%20de\%2005-05-2020.pdf

Dirección de Impuestos y Aduanas Nacionales (DIAN) (2020). Resolución 22 de 18 de marzo de 2020. https://www.dian.gov.co/normatividad/Normatividad/Resoluci\%C3\%B3n\%20000022\%20de\%2018-03-2020.pdf 
Dirección de Impuestos y Aduanas Nacionales (DIAN) (2020). Resolución 38 de 30 de abril de 2020. https://www.dian.gov.co/normatividad/Normatividad/Resoluci\%C3\%B3n\%20000038\%20de\%2030-04-2020.pdf

Ministerio de Salud (2020). Resolución 385 de 12 de marzo de 2020. https://www.minsalud.gov.co/Normatividad_Nuevo/Resoluci\%C3\%B3n\%20No.\%200385\%20 de\%202020.pdf

Presidencia de la República de Colombia (2015). Decreto 1074 de 26 de mayo de 2015. http://wp.presidencia.gov.co/sitios/normativa/decretos/2015/Decretos2015/DECRETO\%201074\%20DEL\%2026\%20DE\%20MAYO\%20DE\%202015.pdf

Presidencia de la República de Colombia (2020). Decreto 401 de 13 de marzo de 2020. https://dapre.presidencia.gov.co/normativa/normativa/DECRETO\%20401\%20 DEL\%2013\%20DE\%20MARZO\%20DE\%202020.pdf

Presidencia de la República de Colombia (2020). Decreto 419 de 18 de marzo de 2020. https://dapre.presidencia.gov.co/normativa/normativa/DECRETO\%20419\%20 DEL\%2018\%20DE\%20MARZO\%20DE\%202020.pdf

Presidencia de la República de Colombia (2020). Decreto 435 de 19 de marzo de 2020. https://dapre.presidencia.gov.co/normativa/normativa/DECRETO\%20435\%20 DEL\%2019\%20DE\%20MARZO\%20DE\%202020.pdf

Presidencia de la República de Colombia (2020). Decreto 438 de 19 de marzo de 2020. https://dapre.presidencia.gov.co/normativa/normativa/DECRETO\%20438\%20 DEL\%2019\%20DE\%20MARZO\%20DE\%202020.pdf

Presidencia de la República de Colombia (2020). Decreto 492 de 28 de marzo de 2020. https://dapre.presidencia.gov.co/normativa/normativa/Decreto-492-28-marzo-2020. pdf

Presidencia de la República de Colombia (2020). Decreto 518 de 4 de abril de 2020. https://dapre.presidencia.gov.co/normativa/normativa/DECRETO\%20518\%20 DEL\%204\%20DE\%20ABRIL\%20DE\%202020.pdf

Presidencia de la República de Colombia (2020). Decreto 520 de 6 de abril de 2020. https://dapre.presidencia.gov.co/normativa/normativa/DECRETO\%20520\%20 DEL\%206\%20DE\%20ABRIL\%20DE\%202020.pdf

Presidencia de la República de Colombia (2020). Decreto 530 de 8 de abril de 2020. https://dapre.presidencia.gov.co/normativa/normativa/DECRETO\%20530\%20 DEL\%208\%20DE\%20ABRIL\%20DE\%202020.pdf 
Presidencia de la República de Colombia (2020). Decreto 535 de 10 de abril de 2020. https://dapre.presidencia.gov.co/normativa/normativa/DECRETO\%20535\%20 DEL\%2010\%20DE\%20ABRIL\%20DE\%202020.pdf

Presidencia de la República de Colombia (2020). Decreto 540 de 13 de abril de 2020. https://dapre.presidencia.gov.co/normativa/normativa/DECRETO\%20540\%20 DEL\%2013\%20DE\%20ABRIL\%20DE\%202020.pdf

Presidencia de la República de Colombia (2020). Decreto 551 de 15 de abril de 2020. https://dapre.presidencia.gov.co/normativa/normativa/DECRETO\%20551\%20 DEL\%2015\%20DE\%20ABRIL\%20DE\%202020.pdf

Presidencia de la República de Colombia (2020). Decreto 560 de 15 de abril de 2020. https://dapre.presidencia.gov.co/normativa/normativa/DECRETO\%20560\%20 DEL\%2015\%20DE\%20ABRIL\%20DE\%202020.pdf

Presidencia de la República de Colombia (2020). Decreto 568 de 15 de abril de 2020. https://dapre.presidencia.gov.co/normativa/normativa/DECRETO\%20568\%20 DEL\%2015\%20DE\%20ABRIL\%20DE\%202020.pdf

Presidencia de la República de Colombia (2020). Decreto 570 de 15 de abril de 2020. https://dapre.presidencia.gov.co/normativa/normativa/DECRETO\%20570\%20 DEL\%2015\%20DE\%20ABRIL\%20DE\%202020.pdf

Presidencia de la República de Colombia (2020). Decreto 573 de 15 de abril de 2020. https://dapre.presidencia.gov.co/normativa/normativa/DECRETO\%20573\%20 DEL\%2015\%20DE\%20ABRIL\%20DE\%202020.pdf

Presidencia de la República de Colombia (2020). Decreto 575 de 15 de abril de 2020. https://dapre.presidencia.gov.co/normativa/normativa/DECRETO\%20575\%20 DEL\%2015\%20DE\%20ABRIL\%20DE\%202020.pdf

Presidencia de la República de Colombia (2020). Decreto 581 de 15 de abril de 2020. https://dapre.presidencia.gov.co/normativa/normativa/DECRETO\%20581\%20 DEL\%2015\%20DE\%20ABRIL\%20DE\%202020.pdf

Presidencia de la República de Colombia (2020). Decreto 639 de 8 de mayo de 2020. https://dapre.presidencia.gov.co/normativa/normativa/DECRETO\%20639\%20 DEL\%208\%20DE\%20MAYO\%20DE\%202020.pdf 
Presidencia de la República de Colombia (2020). Decreto 655 de 13 de mayo de 2020. https://dapre.presidencia.gov.co/normativa/normativa/DECRETO\%20655\%20 DEL\%2013\%20DE\%20MAYO\%20DE\%202020.pdf

Presidencia de la República de Colombia. (2020). Decreto 659 de 13 de mayo de 2020. https://dapre.presidencia.gov.co/normativa/normativa/DECRETO\%20659\%20 DEL\%2013\%20DE\%20MAYO\%20DE\%202020.pdf

Presidencia de la República de Colombia. (2020). Decreto 682 de 21 de mayo de 2020. https://dapre.presidencia.gov.co/normativa/normativa/DECRETO\%20682\%20 DEL\%2021\%20DE\%20MAYO\%20DE\%202020.pdf

Presidencia de la República de Colombia. (2020). Decreto 688 de 22 de mayo de 2020. https://dapre.presidencia.gov.co/normativa/normativa/DECRETO\%20688\%20 DEL\%2022\%20DE\%20MAYO\%20DE\%202020.pdf

Fecha de recepción: 24 de junio de 2020

Fecha de aprobación par 1:08 de septiembre de 2020

Fecha de aprobación par 2: 31 de agosto de 2020 